\title{
EFFECT OF LACTATION ON SERUM TOTAL CHOLESTEROL \& TRIGLYCERIDE
}

\author{
KHADIZA BEGUM ${ }^{1}$, ROKEYA BEGUM ${ }^{2}$, QAZI SHAMIMA AKHTER ${ }^{3}$, NUSRAT SULTANA ${ }^{4}$, SHAMIMA BARI ${ }^{5}$ \\ ${ }^{1}$ Assistant Professor, Physiology, Saphena Women's Dental College, Dhaka \\ ${ }^{2}$ Professor, Chairman, Department of Physiology, Enam Medical College, Savar, Dhaka \\ ${ }^{3}$ Professor, Chairman, Department of Physiology, Dhaka Medical College, Dhaka \\ ${ }^{4}$ Assistant Professor, Physiology, Sahabuddin Medical College, Dhaka \\ ${ }^{5}$ Assistant Professor, Physiology, Ibrahim Medical College, Dhaka
}

\begin{abstract}
Background: There is an association between breast feeding \& maternal lipid profile. Pregnancy related hyperlipidaemia reverse quickly with lactation. Objective; To observe Serum Total cholesterol \& triglyceride in lactating \& nonlactating mother. Method: The present cross sectional study was conducted in the Department of Physiology, Dhaka Medical College, Dhaka, during the period of July 2010 to June 2011. A total 300 subjects were included within the age limit from 20 to 40 years of women. Among them100 were normal healthy subjects \& had child above 3 years were considered as group $A$ (control). The rest 200 women were selected as study subject (group $B$ ) having child between the age 6 weeks to 2 years. Group $B$ is again subdivided into group $B_{1}$ (100 lactating mother) \& group $B_{2}(100$ nonlactating mother). The subjects were selected from pediatric ward \& OPD of pediatrics, DMCH and BSMMU, Dhaka. Data were collected in data collection sheet after taking informed written consent of the subjects. The study parameters total cholesterol \& Triglyceride were done in the Department of Physiology, Dhaka Medical College. The data were analyzed by computer with SPSS programs using unpaired Student 't' test. Results: In group $B_{1}$ total cholesterol \& triglyceride levels were non significantly higher than that of group $A$ but in group $B_{2}$ these values were significantly higher than that of group $A$. Within the study groups all these values were significantly higher in nonlactating mother than lactating mother. It was observed that high level of study parameters were more in $B_{2}$ than that of group $B_{1}$. Conclusion: From the results of the present study it may be concluded that lactation has effect on lowering serum total cholesterol \& triglyceride which may preferably related to health education for the mother.
\end{abstract}

Keywords: Lactation, serum total cholesterol \& triglyceride.

(Bangladesh J Physiol Pharmacol 2013;29(1\&2):1-7.)

\section{INTRODUCTION}

Breast feeding is now a global health issue. Because both baby \& mothers health status are related with it. Breast milk is the most complete form of nutrient for the baby. Lactation exert direct effects on maternal health, some of which may confer both short and long term advantages. In the early postpartum period breast feeding promotes a more rapid return of the reproductive organs to its prepregnant state through the action of oxytocin. It also returns the body weight \& reduces the metabolic changes that occur during pregnancy. ${ }^{1}$

The American Academy of Pediatrics recommends that all infants should be exclusively breast feed through 6 months of age and that breastfeeding should continue

Address for correspondence: Dr. Khadiza Begum, Assistant Professor, Physiology, Saphena Women's Dental College, Dhaka. Telephone: 01712888179; E-mail: begumkhadiza15@yahoo.com until the infant is 1 year of age. Although $80 \%$ of US women initiate lactation, only $36 \%$ report breast feeding and $14 \%$ report exclusive breast feeding their infants at 6 months of age. ${ }^{2}$ Bangladesh is a country usually noted for prolonged breast-feeding. A research work found that after 2 weeks at home, $75 \%$ of the mothers were breastfeeding exclusively but $25 \%$ of mothers failed to continuing exclusive breast-feeding, despite of having been counseled during their hospital stay. ${ }^{3}$

Maternal physiology undergoes many changes during pregnancy. Physiologic adaptations during healthy pregnancy include marked insulin resistance, atherogenic dyslipidaemia, and fat accumulation. But these manifestations are largely reversed back after delivery. If these alterations are failed to reverse \& persist long time after delivery then they causes long lasting adverse physiologic effects \& ultimately develop metabolic syndrome. ${ }^{4}$ Lactation creates a metabolic drain \& associated with favorable effect on maternal 
health. Lactating women exhibits lower plasma glucose $\&$ insulin level, a less atherogenic lipid profile \& greater fat mobilization during the first year of post partum than nonlactating women. ${ }^{2,5,6,7,8}$

Exclusively breast feeding women secrets large amount of cholesterol in to their milk, averaging 15 to $20 \mathrm{mg} / \mathrm{dl}$ of milk, which roughly equals the amount lost by cholesterol lowering medication. ${ }^{9}$

Findings of some studies reported that during lactation there is promote secretion of cholesterol in to milk \& may improve lipid profiles \& reduce the risk for cardiovascular disease. So the long duration of lactation may reduce the development of atherosclerotic damage. ${ }^{1}$ Some other study found a protective association between breast feeding \& incidence of myocardial infarction \& prevalence of hypertension, metabolic syndrome \& dyslipidaemia. ${ }^{7}$

Serum total cholesterol \& serum total triglyceride concentration gradually increase during pregnancy. After delivery, serum triglyceride concentrations declines rapidly to the normal range while total cholesterol and low-density lipoprotein cholesterol declines more slowly. But TG \& LDL level remain more at least 6 weeks of post partum in both lactating and nonlactating women. $6,10,9$ Prolactin increases the clearance of plasma TG and subsequently increases the concentration of HDL \& decrease plasma TG. ${ }^{9}$

In Bangladesh, women are now a day's more educated \& have to go outside \& work side by side with man. Many of them failed to continue breast feed exclusively or adequately. But Government is very concern about breast feeding issue \& takes multiple programs for improving and awareing people about breast feeding. The present study has been designed to assess the Serum TC \& TG status of lactating mother as well as in nonlactating mother.

Lactation has effect on lowering Serum TC \& TG. Present study will provide us knowledge about beneficial effect of breast feeding on maternal health, which will increase the public awareness of breast feeding.

\section{METHODOLOGY}

It was a cross sectional study, carried out in the Department of Physiology, Dhaka Medical College, Dhaka from July, 2010 to June, 2011. A total number of 300 female subjects were included within the age of 2040 years. Group A (control): Consists of 100 apparently healthy, non gravid \& nonlactating mother having child of age above 3 years or mother not in lactation period (to compare with study group).

Group B (study group): Consists of 200 female subjects having baby between 6 weeks to 2 years or mother in lactation period but not in purperium (the period of purperium is avoided as most of the physiological changes during pregnancy revert back to normal with in this period) Group $B$ is again divided into group $B_{1}$ : 100 lactating mother, $B_{2}$ : 100 non lactating mother. All subjects were selected from the pediatric indoor \& out door, of Dhaka Medical college Hospital (DMCH) and from BSMMU, Dhaka. All the subjects were belonged to middle socioeconomic status. Pregnant mother with baby below 2 years or mother having adopted child or mother having baby $<6$ weeks (as it is the period of puerpurium) were excluded from the study. Mother with heart disease, liver disease or kidney disease or any endocrine disease like thyroid disease were also excluded. After selection of subjects the purpose of the study was explained to each subject with a cordial attitude giving emphasis on the benefits they would obtain from the study. They were encouraged for their voluntary participation. They were also allowed to withdraw themselves as soon as they wish. All the subjects were requested to be empty stomach before giving blood sample. Before taking blood sample an informed written consent was taken from each subject. Then blood was collected. Ethical clearance was taken from ethical review committee of Dhaka Medical College. Data was collected in a predesigned data collection sheet. With all aseptic precaution $5 \mathrm{ml}$ of venous blood was drawn from the antecubital vein by a disposable plastic syringe. Blood was allowed to clot and then centrifuged at a rate of $3000 \mathrm{rpm}$ and supernatant clear serum was separated. Serum was taken in to eppendrof tube and was preserved in refrigerator at $-28^{\circ} \mathrm{C}$ in Department of Physiology of Dhaka Medical College, Dhaka. Estimation of serum Total cholesterol \& triglyceride were done by

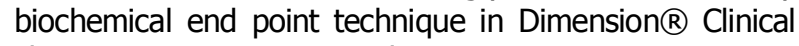
chemistry system in same place.

Statistical analysis were done by Student's unpaired't' test. Correlation was analyzed by Pearson's correlation test. $P$ value $<0.05$ was taken as level of significance.

\section{RESULTS}

In the present study, mean TC, TG levels in lactating mothers were nonsignificantly higher than that of baseline control group. In nonlactating mothers the mean TC, TG levels were higher than that of control group \& was statistically significant $(p<0.01 \& p<0.001$ respectively). The present study showed significant lower level of TC, TG ( $p<0.01 \& p<0.001$ respectively) in lactating mother than nonlactating mother. Mean duration of lactation showed negative correlation with TC, TG in lactating mother \& TC in non lactating mothers. But positive correlation was observed with TG level in nonlactating mothers. Among them the relationship was significant for TC in lactating mother where as other relationships was not statistically significant.

Total Cholesterol level $>200 \mathrm{mg} / \mathrm{dl}$ were present in $13(15.5 \%)$ subjects in group $A, 25(29.8 \%)$ subjects in group $B_{1} \& 46(54.8 \%)$ subjects in group $B_{2}$. Triglyceride levels $\geq 150 \mathrm{mg} / \mathrm{dl}$ were present in $9(12.7 \%)$ subjects in group $A, 4(19.7 \%)$ subjects in group $B_{1} \& 48(67.6 \%)$ subjects in group $B_{2}$. 
Table I

Serum Total cholesterol level in different groups

\begin{tabular}{c|cc}
\hline Groups & $\mathbf{n}$ & $\begin{array}{c}\text { Total Cholesterol }(\mathbf{m g} / \mathbf{d l}) \\
\text { (Mean } \pm \text { SD) }\end{array}$ \\
\hline$A$ & 100 & $175.23 \pm 36.94$ \\
$\mathrm{~B}$ & 100 & $177.23 \pm 35.19$ \\
$\mathrm{~B}_{2}$ & 100 & $193.55 \pm 38.58$ \\
\hline
\end{tabular}

Statistical analysis

\begin{tabular}{c|c}
\hline Groups & $\begin{array}{c}\text { Total Cholesterol }(\mathbf{m g} / \mathrm{dl}) \\
(\text { Mean } \pm \text { SD) }\end{array}$ \\
\hline A vs $B_{1}$ & $0.695^{\mathrm{ns}}$ \\
$\mathrm{A}$ vs $\mathrm{B}_{2}$ & $0.001^{* *}$ \\
$\mathrm{~B}_{1}$ vs $\mathrm{B}_{2}$ & $0.002^{* *}$ \\
\hline
\end{tabular}

Unpaired Student's 't' test was performed to compare between groups.

The test of significance was calculated and $p$ values $<0.05$ was accepted as level of significance.

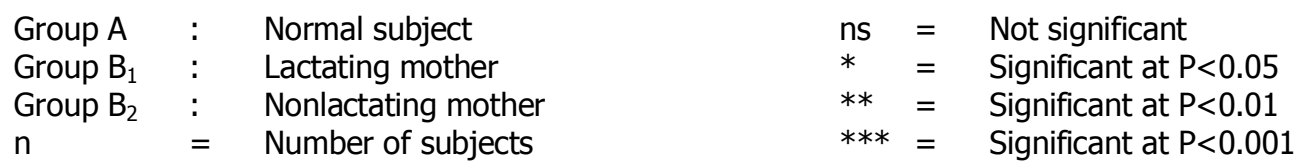

Table II

Serum Total Triglyceride level in different groups

\begin{tabular}{c|cc}
\hline Groups & $\mathbf{n}$ & $\begin{array}{c}\text { Triglyceride }(\mathbf{m g} / \mathbf{d l}) \\
\text { (Mean } \pm \text { SD) }\end{array}$ \\
\hline$A$ & 100 & $97.99 \pm 49.08$ \\
$\mathrm{~B}$ & 100 & $107.34 \pm 61.89$ \\
$\mathrm{~B}_{2}$ & 100 & $149.98 \pm 61.45$ \\
\hline
\end{tabular}

Statistical analysis

\begin{tabular}{c|c}
\hline Groups & $\begin{array}{c}\text { Total Cholesterol }(\mathrm{mg} / \mathrm{dl}) \\
(\text { Mean } \pm \text { SD) }\end{array}$ \\
\hline $\mathrm{A}$ vs B 1 & $0.238^{\mathrm{ns}}$ \\
$\mathrm{A}$ vs B & $0.8001^{* * *}$ \\
$\mathrm{~B}_{1}$ vs $\mathrm{B}_{2}$ & $0.0001^{* * *}$ \\
\hline
\end{tabular}

Unpaired Student's 't' test was performed to compare between groups.

The test of significance was calculated and $p$ values $<0.05$ was accepted as level of significance.

$\begin{array}{llllll}\text { Group } A & : & \text { Normal subject } & \text { ns } & = & \text { Not significant } \\ \text { Group } B_{1} & : & \text { Lactating mother } & * & = & \text { Significant at } \mathrm{P}<0.05 \\ \text { Group } \mathrm{B}_{2} & : & \text { Nonlactating mother } & * * & = & \text { Significant at } \mathrm{P}<0.01 \\ \mathrm{n} & = & \text { Number of subjects } & * * * & = & \text { Significant at } \mathrm{P}<0.001\end{array}$


Mean total cholesterol and triglyceride in different groups

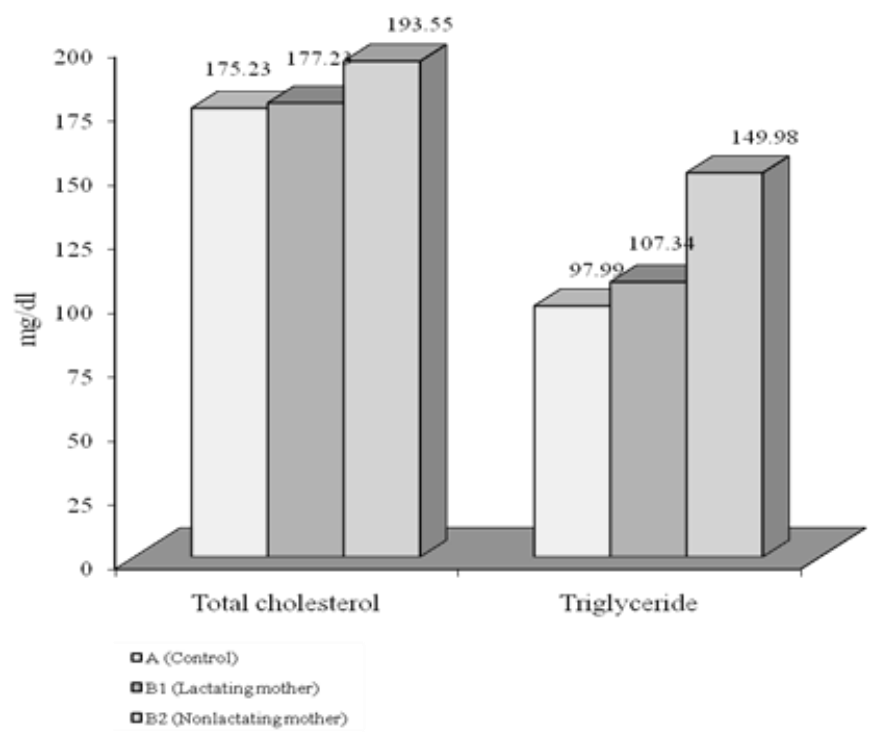

Figure1: Mean serum total cholesterol \& triglyceride levels in different groups

Frequency distribution of subjects by total cholesterol in different groups

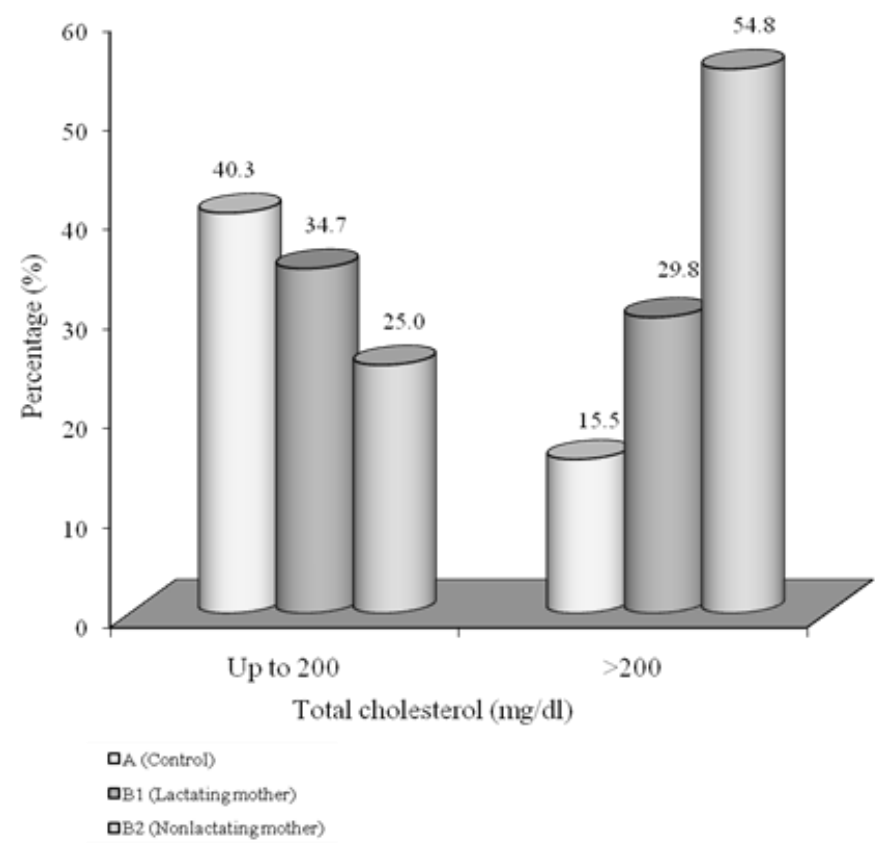

Figure 2: Frequency distribution of subjects by serum total cholesterol in different groups 


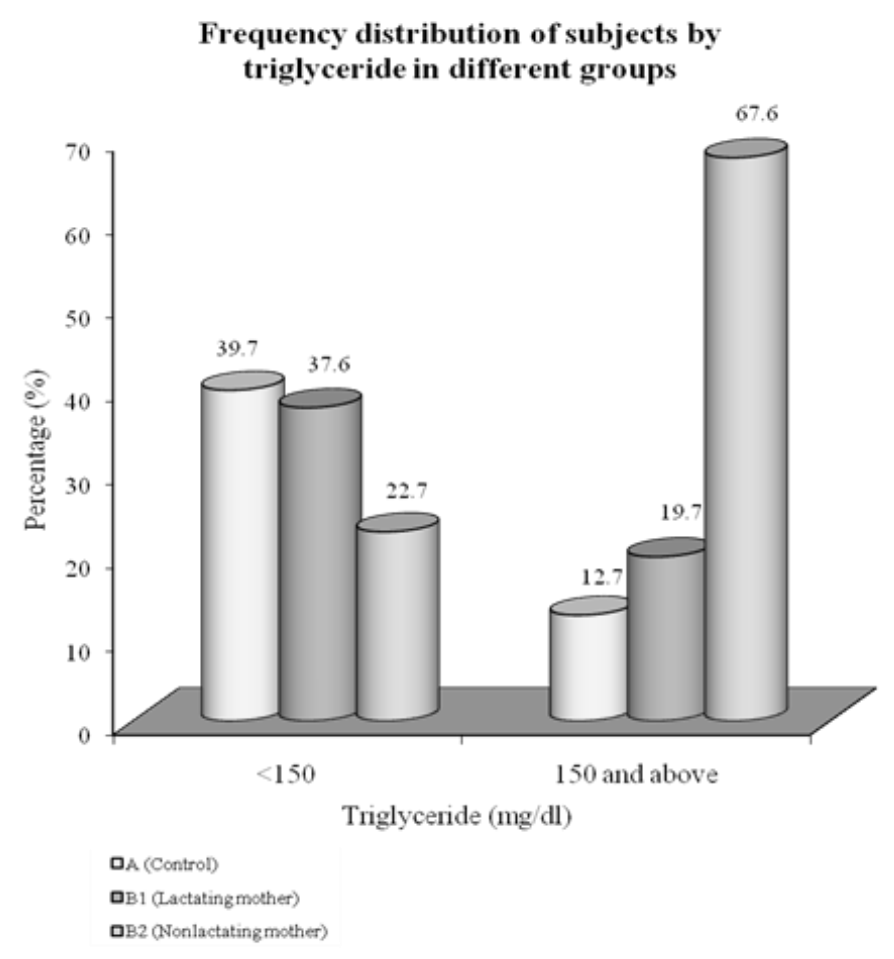

Figure 3: frequency distribution of subjects by serum triglyceride in different groups

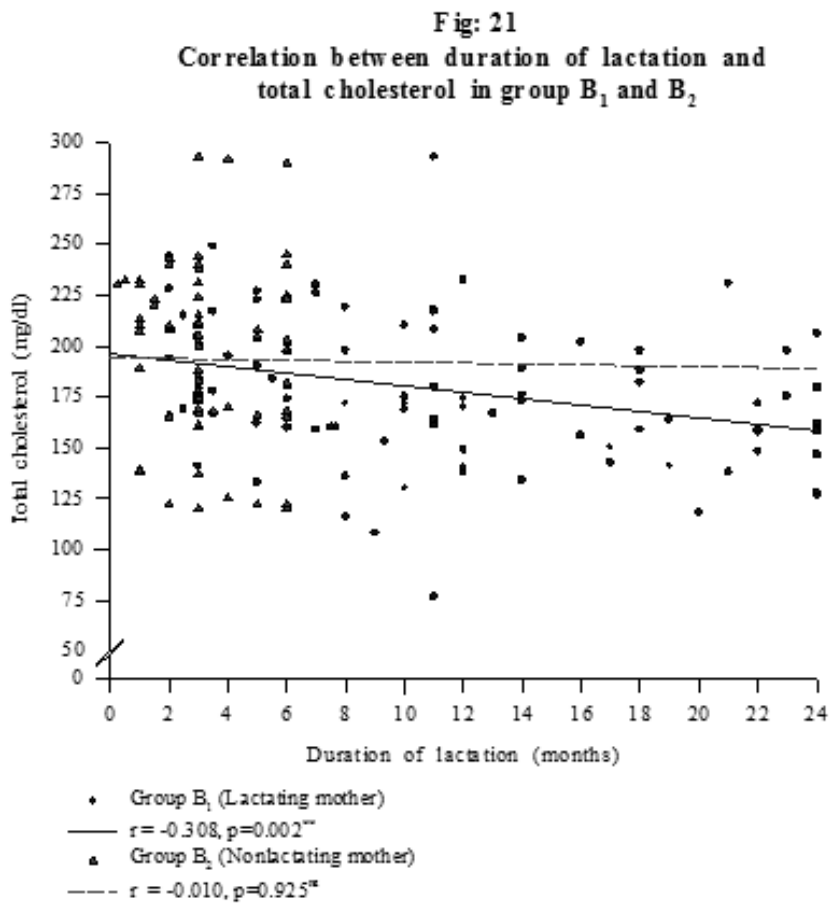

Figure 4: Correlation between mean duration of lactation \& serum total cholesterol in group $B_{1} \& B_{2}$ 
Fig: 22

Correlation between duration of lactation and triglyceride in group $B_{1}$ and $B_{2}$

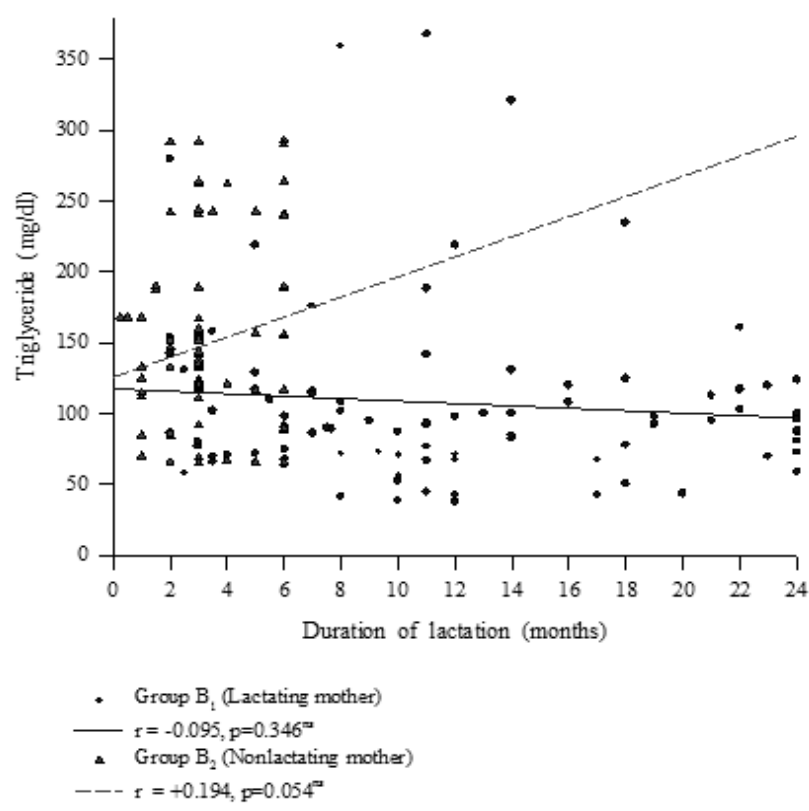

Figure 5: Correlation between mean duration of lactation \& serum triglyceride in group $B_{1} \& B_{2}$

\section{DISCUSSION}

The present study was carried out to observe serum TC \& TG in lactating( group $B_{1}$ ) \& nonlactating mother (group $B_{2}$ ) and also in age matched apparently healthy adult female who are not in lactation period ( group A) for comparison.

Distributions of the parameters were observed among the groups. All the parameters were also correlated with duration of lactation in both study groups to observe any relationship with the duration of lactation.

In the present study, findings of all the parameters in healthy subjects or baseline control group were almos $^{+}$within normal range and also similar to those reported by the other investigators from different counties. ${ }^{11,12,7}$ However no published data of these study parameters of lactating mother are available for comparison in our country.

In the present study mean TC, TG levels in lactating mothers were nonsignificantly higher but in nonlactating mothers these levels were significantly higher than that of baseline control. The present study showed significant lower level of TC, TG in lactating mother than nonlactating mother. Mean duration of lactation showed negative correlation with TC, TG in lactating mother \& TC in non lactating mothers .But positive correlation was observed with TG level in nonlactating mothers.

These findings are in agreement with other study $^{14}$, they found that serum TC decreased significantly within 3 months after delivery \& further significant decrease occurred during the following 9 months. They also suggested that serum TG decrease with in 3 month after delivery in lactating mother but no more significantly later.

Other investigators found that serum TG levels returned to base line earlier in lactating than in nonlactating women. ${ }^{14}$ This study also in agreement with the present study.

Decreased level of serum TG \& TC in lactating mother was reported by some authors. ${ }^{15,16}$ They stated that pregnancy associated increase in serum triglyceride $\&$ total cholesterol level resolve more rapidly in women who breast feed than women who do not. They reported that these favorable changes in lipid metabolism persist after weaning \& has a long lasting effect on maternal metabolism. This study is also in agreement with the present study.

After parturition there is change from overall insulin resistance to insulin sensitivity. Low insulin levels lead to increase fat mobilization and transfer to the 
mammary gland. Insulin stimulates glucose and lipogenesis and controls mammary gland lipoprotein lipase. As a result lactating women exhibit lower blood glucose \& insulin concentrations along with higher rates of glucose production and lypolysis compared with nonlactating women. ${ }^{17,18}$

Non lactating mother fail to decrease the fat stores that were stored during pregnancy lead to obesity. Hyperinsulinemia may enhance output of VLDL lipoprotein and triglycerides. ${ }^{19}$

Lactating mother secrete large amounts of cholesterol into their milk averaging 15- $20 \mathrm{mg}$ cholesterol / $100 \mathrm{ml}$ of milk among the women who feed exclusively to the baby. As a result there is an output of average $150 \mathrm{mg} /$ day which roughly equals the amount of cholesterol lost by cholesterol lowering drug. Lactation decreases the cholesterol level which prevents the risk of cardiovascular disease ${ }^{9}$.

Milk triglycerides \& cholesterol are known to be derived from lipoproteins as well as de novo synthesis in the mammary gland. Prolactin activates an enzyme in the mammary gland that increases the clearance of plasma TG and increases the concentration of $\mathrm{HDL}^{9,6}$.

\section{CONCLUSION}

Present study revealed that lactating mother has lower TC, TG level than that of non lactating mother. Lower percent of frequency distribution of TC \& TG was seen in lactating mother than that of non lactating mother. Duration of lactation has significant negative correlation with TC level in lactating mother.

From the above discussion it may be concluded that lactation has effect on lowering serum TC \& TG . It can play role in improving maternal health $\&$ this beneficial effect should be included with in the health education.

\section{ACKNOWLEDGEMENT}

The authors thank all the participants of the study. The authors are also grateful to the Department of Physiology for all kind of support.

\section{REFERENCES}

1. Heinig MJ \& Kathryn GD. Health effects of breast feeding for mothers: A critical review. Nutrition Research Reviews.1997; 10: $35-56$.

2. Gundeson EP. Breast feeding after gestational diabetespregnancy. Diabetes care 2007; 30: 161-168.

3. Haider R, Kabir, Hamadani J.D, Habte D. Reasons for failure of breast-feeding counseling mothers' perspectives in Bangladesh. Bulletin of the World Health Organization1997;75: 191-196.

4. Gundeson EP, Jacobs DR, Chiang $V$, Lewis CE, Tsai A Quesenberry Jr, Sidney S.Child bearing is associated with higher incidence of the metabolic syndrome among women of reproductive age controlling for measurements before pregnancy : the CARDIA study. American Journal of Obstet Gynecol 2009; 201( 2): 177

5. Manus MC, Chingham I, Watson A, Harker $L$. Beta cell function and visceral fat in lactating women with a history of gestational DM. Metabolism 2001; I.50: 715-19.

6. Knopp RH, Walden CE, Wahl PW , Bergelin R, Chapman M, Irvine $\mathrm{S}$. Effect of post partum lactation on lipoprotein lipids and appoprotines. J Clin Endocrinol Metab1985; 60:542-7

7. Stuebe AM \& Janet WRE. The reset hypothesis: Lactation \& maternal metabolism. Am J Perinatol 2009;.26:81-88.

8. Dewey KG, Heinig MJ \& Nommsen LA. Maternal weight-loss patterns during prolonged lactation. Am J Clin Nutr1993; 58: 162-166.

9. Kallio MJ, Siimes MA, Perheentupa J, Miettinen TA. Serum cholesterol \& lipoprotein concentrations in mothers during and after prolonged exclusive lactation. Metabolism 1992; 41(12): $1327-30$.

10. Jimenez DM, Ramon CJ, Procovi M, Romio MA, Martinz H, Grande F. Longitudinal study of plasma lipids and lipoprotein cholesterol in normal pregnancy and puerperium. Gynecological and obstetric investigation1988; 25: 158-164.

11. Gundeson EP, David RJ , Vicky C, Cora EL, Juanan F, Charles JQJ, Stephen S. Duration of lactation and incidence of metabolic syndrome in women of reproductive age according to gestational diabetes mellitus status : A 20 year prospective study in CARDIA. Diabetes 2010;59: 495-504.

12. Ohlin A \& Rossner S. Maternal body weight development after pregnancy Int J Obes1990; 14( 2):159-173.

13. Erkkola R, Viikari J, Irjala K, Solakivi- Jaakkola T. One year follow up of lipoprotein metabolism after pregnancy ', Bio Res Pregnancy Perinatol1986; 7( 2): 47- 51.

14. Darmady JM \& Postle AD.Lipid metabolism in pregnancy. $\mathrm{Br}$ J Obstet Gynaecol1982; 89( 3): 211-5

15. Gundeson EP. Breast feeding after gestational diabetespregnancy', Diabetes care 2007;30: 161-168.

16. Kjos SL, Olivia H, Richard ML, Thomas AB, Daniel RM. The effect of lactation on glucose \& lipid metabolism in women with recent gestational DM. Obstet Gynecol1993;.82: 451-5.

17. Tigas S, Sunchag A, Haymond MW. Metabolic adaptation adaptation to feeding and fasting during lactation in human. J Clin Endocrinol Metab 2002; 87: 302-307.

18. Diniz JM, Teresa HM, Costa D.'Independent of body adiposity, breast feeding has a protective effect on glucose metabolism in young adult women. British Journal of Nutrition 2004; 92: 905912.

19. Grundy SM, Bryan HB, James IC, Sidne CS, Claude L.'Definition of Metabolic syndrome' Report of the National Heart, Lung and Blood Institute/American Heart Association Conference on Scientific Issues Related to Definition 2004; 109:433-438. Viewed on 5 th April, 2011. <http://circ.ahajournals .org/cgi/content/full/109/3> 